\title{
Iron Deficiency And Child Health: A Permanent Challenge
}

\author{
Luiz Antonio Del Ciampo and Ieda Regina Lopes Del Ciampo
}

\begin{abstract}
Iron deficiency (ID) is the most common widespread nutritional disorder in the world in both developing and developed countries and remains a leading cause of anemia mainly affecting children between the ages of 6 to 59 months. ID can be understood as a state in which there is insufficient total body iron to maintain normal physiologic functions and which can vary in intensity from mild forms to the most severe condition which is anemia. The prevalence of ID among children under the age of three years old is high, varying according to the regions of the world, between about $10 \%$ in the USA to $33 \%$ in African countries, South-East Asia and Eastern Mediterranean. In view of the importance of ID for human health, with its physical, emotional, social and economic repercussions, it is important to know all aspects related to this nutritional deficiency so that actions for prevention, identification and early treatment of those affected can be developed. This article briefly reviews the importance of iron for children's health, highlighting metabolism, clinical changes, diagnosis and measures that can solve or minimize this serious public health problem.
\end{abstract}

Index Terms - Iron deficiency, iron anemia, child health, nutrition.

\section{INTRODUCTION}

Iron deficiency (ID) is the most common widespread nutritional disorder in the world in both developing and developed countries and remains a leading cause of anemia mainly affecting children between the ages of 6 to 59 months $[1,2,3]$ ID can be understood as a state in which there is insufficient total body iron to maintain normal physiologic functions and which can vary in intensity from mild forms to the most severe condition which is anemia [4]

Although this condition can affect individuals in any age group children are part of one of the most affected groups due to a great amount of iron needed to synthesize new tissues, expanding blood volume and to maintain correct hemoglobin concentration $[5,6]$.

The prevalence of ID among children under the age of three years old is high, varying according to the regions of the world, between about $10 \%$ in the USA to $33 \%$ in African countries, South-East Asia and Eastern Mediterranean, affecting more than 300 million children worldwide $[4,7,8]$.

In view of the importance of ID for human health, with its physical, emotional, social and economic repercussions, it is important to know all aspects related to this nutritional deficiency so that actions for prevention, identification and

Published on April 13, 2020.

Luiz Antonio Del Ciampo, Department of Puericulture and Pediatrics, Faculty of Medicine of Ribeirão Preto, University of São Paulo, Brazil.

(corresponding e-mail: delciamp@fmrp.usp.br).

Ieda Regina Lopes Del Ciampo, Department of Medicine, Federal University of São Carlos, Brazil.

(e-mail: irciampo@gmail.com). early treatment of those affected can be developed. This article briefly reviews the importance of iron for children's health, highlighting metabolism, clinical changes, diagnosis and measures that can solve or minimize this serious public health problem.

Iron

Iron is a metal highly abundant in the earth's crust, biologically classified as a micronutrient, essential for human life and that can be found, with exception of some species of lactobacillus, in all living being cells [2,9]. It is fundamental for the transportation of oxygen, is an integral part of some proteins (hemoglobin, myoglobin, flavoprotein, lactoferrin) and participates in more than 200 enzymatic systems that are essential for cellular functions such as adenosine triphosphate generation, cytochromes, catalases, and peroxidases $[2,5,10,11]$.

The distribution of iron in the body shows that $65 \%$ is linked to hemoglobin, $4 \%$ as myoglobin, $1 \%$ hemic compounds, $0.1 \%$ combined with transferrin. Between $15 \%$ and $30 \%$ are stored in the liver, spleen and bone marrow in the form of ferritin or hemosiderin [2,5]. At birth healthy term children have high to normal hemoglobin concentrations $(15-17 \mathrm{~g} / \mathrm{dL})$ and iron stores which remain iron replete until 6 months of life. After birth, iron can be obtained by means of three dietetic forms: breast milk (iron bound to lactoferrin with high bioavailability), heme iron and nonheme iron forms [11].

Heme iron is found in the structure of the protoporphyrin ring of hemoproteins, being soluble in the alkaline medium of intestinal light and easily absorbed $[9,12]$, while nonheme iron complex (from plant sources and bound to organic molecules in the form of ferric iron) is degraded during digestion in the gastrointestinal tract owing to the action of pepsin and hydrochloric acid. In addition to dietary sources, humans have complex mechanisms for conserving recycled iron from the release of deposits from the body and the breakdown of red blood cells $[2,13]$.

Iron absorption occurs by the mature enterocytes in the villus of duodenum and the upper part of the jejunum (where it is oxidized) and initially linked to specific sites on the mucous membrane. From there it is transported to the basolateral membrane where it binds to transferrin $[9,12,14]$. Iron status is regulated by intestinal absorption and transport. Absorption is regulated by the peptide hormone hepcidin [7] - a negative iron regulator, synthesized in the liver and secreted into the circulation - which acts primarily on a basolateral surface of enterocytes and facilitates the iron uptake into the plasma from the intestine $[3,15,16]$.

In order to be better absorbed iron must be presented with high bioavailability (which is the fraction effectively absorbed and used). The more soluble the iron compound, 
the greater is the potential absorption. Ferrous iron form has generally been assumed to be better absorbed than ferric iron $[2,5,12]$. Compounds such as ascorbic acid, fructose, citric, malic, lactic, succinic and tartaric acids, that reduce iron from ferric to ferrous generally increase bioavailability [2]. On the other hand, plant compounds (polyphenols, tea, coffee, chocolate, spices, seeds), oxalic and phytic acids, interactions with metallic or mineral ions (calcium, zinc, cobalt, manganese, cupper) and synthetic additives and chelators (such as sodium alginate), tetracyclines and ethylenediaminetetraacetic acid (EDTA) form insoluble precipitates and inhibit absorption [2,16]. Only small amounts of iron are excreted by the body through bile, feces, bleeding and epithelial peeling.

\section{ID CAUSES}

There are several causes for ID and can be classified as [4,5,15,17-20]:

\section{A. Prenatal and Perinatal}

Maternal iron deficiency, fetal-maternal hemorrhage, twin-twin transfusion syndrome, prematurity.

\section{B. Postnatal}

Poor supply dietary deficiency, poor absorption (duodenal disorders, giardiasis), imperfect metabolism, high loss (gastrointestinal blood loss due to hookworm infestation, inflammatory bowel disease, cow milk protein proctocolitis.

\section{ID EFFECTS}

ID effects are particularly important on cells with high metabolic rates [21]. Even before the anemia is installed, the reduction of iron in the body can cause several changes in all systems due to the reduced effectiveness of and cytokine production by lymphocytes [7,11], changes in the phagocytic activity of macrophages, oxidative burst in neutrophils, and slow neural transmission [22,23].

Although ID is associated with multiple health problems, including anemia and defective organ functions, children with ID can be seemingly normal because this condition is frequently asymptomatic and thus may often go underdiagnosed. Most mild symptomatic patients may experience fatigue, pallor, reduced interest in physical activities, loss of appetite, pica (craving for nonfood items), irritability and increased absorption of heavy metals intoxication. In more intense cases can be observed sensitivity to cold, angular cheilitis, koilonychia, spoon nails, hair loss, dry and rough skin, and glossitis [24,15,20,24-26]. Some authors have described other problems related to ID such as restless leg syndrome $[15,26,27]$, attention deficit hyperactivity disorder ADHD [4], sleep disorders [4,22,27], recurrent acute respiratory tract infections and gastroenteritis [28,29], thrombosis $[4,30,31]$.

\section{IRON AND THE DEVELOPMENT OF CENTRAL NERVOUS SYSTEM}

The blood-brain barrier controls the iron concentration in the cerebral structures and brain's iron status is compromised before the iron status of the red blood cells
$[21,32]$. Brain iron is vital to multiple functions including adenosine triphosphate (ATP) synthesis, neurotransmitter (dopamine, serotonin) synthesis and myelination [25,33]. Tissue iron is more concentrate in basal ganglia structures such as globus pallidus, caudate, putamen and nucleus accumbens [34, 35].

Until the age of three the central nervous system (CNS) is in rapid anatomical and functional development and suffers great physical and emotional influences from the external environment. ID has been associated with impaired brain development and long-term damage of behavioral and cognitive performance that may irreversible [35-38]. The most important changes that can be observed in the CNS due to ID are $[2,11,17,22,25,39-46]$ : reduced myelination, slower neural conduction velocity, high prevalence of abnormal neurologic reflexes, decreased psychomotor and mental developments, impaired hippocampal function, decrease in verbal abilities, low discrimination memory, poor mathematical and writing abilities, deficits in visual and auditory systems, anxiety and depression symptoms, altered child-mother interaction [48,49].

\section{ID DIAGNOSIS}

A presumptive diagnosis of ID is made by the combination of risk assessment and laboratory findings [50]. Every child should have a careful prenatal information (gestational age, weight birth, twinning, blood loss), dietary history and review of risk factors for ID (infection, intestinal parasitic infestation, chronic diseases) and undergo a complete physical examination [51]. The World Health Organization recommends the use of low concentrations of ferritin $(<12 \mu \mathrm{g} / \mathrm{L}$ in children $<5$ years or $<15 \mu \mathrm{g} / \mathrm{L}$ in children $\geq 5$ years) as ferritin reflects iron stores in the body [52]. The American Academy of Pediatrics suggests a routine screening for ID/ID anemia for all children ate the age of 12 months (33).

\section{TREATMENT}

To correct the ID it is necessary to identify and treat the basic causes (human hookworm is one of the most important and neglected of all human parasitic infection which afflicts more than 470 million people) and establish a plan of actions aimed at $[15,33,53,54]$ :

1. dietary modifications to address the underlying etiology of the iron deficiency,

2. ensure adequate consumption of iron complementary foods rich in vitamin $\mathrm{C}$

3. appropriate dose and scheduling of iron therapy,

4. follow-up assessment for response and control.

Oral iron treatment id preferred primarily because is economical and has few side effects. The most used dose is $3-6 \mathrm{mg} / \mathrm{Kg} /$ day of sulfate, gluconate, fumarate, succinate, carbonyl or polysaccharide complex iron salts, for 3 consecutive months [26].

\section{THE IMPORTANCE OF DIET}

Children must obtain about $30 \%$ of their daily iron from diet to provide the necessary for new tissues, growth spurt and red blood cells $[5,15]$. The adequate intake of iron for 0 
- 6 months old infant has been estimated as $0,27 \mathrm{mg} /$ day and the recommended daily allowance for $7-12$ months of age is $11 \mathrm{mg} /$ day [12]. Therefore, in addition to breastfeeding, it is necessary to eat foods from animal sources (heme iron) such as beef, chicken, fish, seafood, eggs, and from vegetal sources (cereals, dried fruits, dark green vegetables) in quantities that can also supply all the daily energy needs. The combination of foods of plant origin with sources of heme iron (animal origin) favors the absorption of ingested iron.

\section{IRON SUPPLEMENTATION}

Iron supplementation for children at risk for ID has been widely discussed. Several authors agree that the critical period for providing supplementation to ensure iron deficiency to protect neurodevelopment is earlier in life and late fetal period $[21,55,56]$. World Health Organization recommends iron supplementation to prevent ID in instances where the prevalence of anemia is $40 \%$ or higher [4]. This supplementation can be done with some types of iron salts like sulfate, fumarate, succinate or gluconate [15] and close monitoring of iron status and iron homeostasis is very important [21] in order to detect possible adverse effects such as staining of the teeth, dyspepsia, nausea, vomiting, abdominal pain, constipation, diarrhea, and alterations in the composition of the gut microbiome [15]. Supplementation programs need to be monitored and motivated by the target population to ensure that iron is administered over time, avoiding abandonment for unjustified reasons [57]. In addition, it is necessary to know the individual and collective health conditions in order to prevent the indiscriminate administration of iron from causing harm, as in the case of malaria-endemic regions [58]. In malariaendemic areas, the provision of iron supplementation in infants and children should be done in conjunction with public health measures to prevent, diagnose and treat malaria [59-60].

\section{FOOD FORTIFICATION}

Fortification of foods with iron has also been a strategy adopted in several countries. Several challenges need to be overcome so that the iron incorporated as a fortification is well tolerated, easily absorbed, does not alter the taste or appearance of the food or cause adverse effects. The most important results have been achieved with powder infant milk formulas [61], cereal foods for the weaning [62], maize flour [63], iron-fortified juice [64], bouillons [65], and water [66].

\section{Actions Against ID}

Given the magnitude of this serious public health problem, many actions have been developed worldwide [3,16,20,67]:

a) increase and improve prenatal care,

b) encourage exclusive breastfeeding,

c) consume of iron fortified formula after weaning,

c) educating the family with nutritional recommendations,

d) increase access to and consumption of iron-rich foods,

e) enrichment of foods (rice, maize, flour, cornmeal) with

\section{CONCLUSION}

ID is one of the main public health problems in the world and reducing its prevalence is a priority because long-term negative effects on physical and mental health, educational attainment, and job potential impact in the future of people and nations lowering intelligence quotients [3,7,15,35]. All efforts should be made at individual and collective levels, mobilizing people from the health, education, food security and the whole of society to improve the living conditions of populations most vulnerable to nutritional deficiencies and their undesirable consequences.

\section{REFERENCES}

[1] Juul SE, Derman RJ, Auerbach M. Perinatal iron deficiency: implications for mothers and infants. Neonatology 2019;115:269-274.

[2] Subramanian G, Girish M. Iron deficiency anemia in children. Indian J Pediatr 2015;82:558-564.

[3] Lonnerdal B, Kelleher SL. Iron metabolism in infants and children. Food Nutr Bull 2007;28:S491-S498.

[4] Bailey RL, West KP Jr, Black RE. (2015). The epidemiology of global micronutrient deficiencies. Ann Nutr Metab 2015;66:22-23.

[5] Blanco-Rojo R, Vaquero MP. Iron bioavailability from food fortification to precision nutrition: a review. Inn Food Sci Emerg Tech 2019;51:126-138.

[6] Unger SL, Fenton TR, Jetty R, Critch JN, O'Connor DL. Iron requirements in the first 2 years of life. Paediatr Child Health 2019;24:555-556.

[7] Means RT. Iron deficiency and iron deficiency anemia: implications and impact in pregnancy, fetal development, and early childhood parameters. Nutrients 2020;12:447-458.

[8] Stelle I, Kalea AZ, Pereira DIA. Iron deficiency anaemia: experiences and challenges. Proc Nutr Soc 2019;78:19-26.

[9] Camaschella C. Iron deficiency. Blood 2019;133:30-39.

[10] Lopez A, Cacoub P, Macdougall IC, Peyrin-Biroulet L. Iron deficiency anaemia. Lancet 2016;387:907-916.

[11] Cerami C. Iron nutriture of the fetus, neonate, infant, and child. Ann Nutr Metab 2017;71(Suppl 3):8-14.

[12] Cappellini MD, Musallam KM, Taher AT. Iron deficiency anaemia revisited. J Int Med 2020;287:153-170.

[13] Lönnerdal B. Development of iron homeostasis in infants and young children. Am J Clin Nutr 2017;106(Suppl 6):1575S-1580S.

[14] Anderson GJ, Frazer DM. Current understanding of iron homeostasis. Am J Clin Nutr 2017;106(Suppl 6):1559S-1566S.

[15] Camaschella C. Iron deficiency: new insights into diagnosis and treatment. Hematology Am Soc Hematol Educ Program 2015;2015:813.

[16] Powers JM, Nagel M, Raphael JL, Mahoney DH, Buchanan GR, Thompson DI. Barriers to and facilitators of iron therapy in children with iron deficiency anemia. J Pediatr 2020;219:202-208.

[17] Lozoff B. Iron deficiency and child development. Food Nutr Bull 2007;28:560-568.

[18] Olives JP. Causes of iron deficiency in children. Arch Pediatr 2017;24(5S):5S2-5S5.

[19] Mantadakis E, Zikidou P, Tsouvala E, Thomaidis S, Chatzimichael A. Severe iron deficiency anemia and anasarca edema due to excessive cow's milk intake. Turk J Ped 2019;61:102-106.

[20] World Health Organization. Serum ferritin concentrations for the assessment of iron status and iron deficiency in populations. Vitamin and Mineral Nutrition Information System. World Health Organization. 2011.

[21] Lozoff B, Smith JB, Kaciroti N, Clark KM, Guevara S, Jimenez E. Functional significance of early-life iron deficiency: outcomes at 25 years. J Pediatr 2013;163:1260-1266.

[22] Ganz T. Macrophages and iron metabolism. Microbiol Spectr 2016;4:1-10

[23] Sypes EE, Parkin PC, Birken CS, Carsley S, MacArthur C, Maguire $\mathrm{JL}$ et al. Higher body mass index is associated with iron deficiency in children 1 to 3 years of age. J Pediatr 2019;207:198-204.

[24] Chandra J. Treating iron deficiency anemia. Indian J Pediatr 2019;86:1085-1086.

[25] East P, Delker E, Blanco E, Encina P, Lozoff B, Gahagan S. Effect of infant iron deficiency on children's verbal abilities: The Roles of child affect and parent unresponsiveness. Matern Child Health J 2019;23:1240-1250. 
[26] Munzer T, Felt B. The role of iron in pediatric restless legs syndrome and periodic limb movements in sleep. Semin Neurol 2017;37:439445.

[27] Georgieff MK. Iron assessment to protect the developing brain. Am J Clin Nutr 2017;106(Suppl 6):1588S-1593S

[28] Ceren K, Lale O, Taner S, Z Ecevit, Murat Ö, Varan B. Thrombosis in iron deficiency and iron deficiency anemia: A review of our cases and the relevant literature. Open Acc J Oncol Med 2018;2:157-172.

[29] Akcan FA, Dündar Y, Akcan H, Cebeci D, Sungur MA, Ünlü İ. The association between iron deficiency and otitis media with effusion. J Int Adv Otol 2019;15:18-21.

[30] V. Kılcı, Olcay L, Özdemir B, Fettah A, Çolak MY. Children with iron deficiency anemia have tendency to hypercoagulation: An evaluation by thromboelastography. Turk J Haematol 2020;37:59-62.

[31] Leung W, Singh I, McWilliams S, Stockler S, Ipsiroglu OS. Iron deficiency and sleep - a scoping review. Sleep Med Rev 2020 Available online 8 February 2020, 101274

[32] Jonker FA, van Hensbroek MB. Anaemia, iron deficiency and susceptibility to infections. J Infect 2014;69(Suppl 1):S23-S27.

[33] Jayaweera JAAS, Reyes M, Joseph A. Childhood iron deficiency anemia leads to recurrent respiratory tract infections and gastroenteritis. Sci Rep 2019;9:12637-12645.

[34] Vallée L. Iron and Neurodevelopment. Arch Pediatr 2017;24(5S):5S18-5S22.

[35] Larsen B, Bourque J, Moore TM, Adebimpe A, Calkins ME, Elliott MA et al. Longitudinal development of brain iron is linked to cognition in youth. J Neurosc 2020;40:1810-1818

[36] Georgieff MK. Long-term brain and behavioral consequences of early iron deficiency. Nutr Rev 2011;69(suppl 1):S43-S48.

[37] Georgieff MK. Iron assessment to protect the developing brain. Am J Clin Nutr 2017;106(Suppl):1588S-1593S.

[38] Roncagliolo M, Garrido M, Walter T, Peirano P, Lozoff B: Evidence of altered central nervous system development in infants with iron deficiency anemia at $6 \mathrm{mo}$ : delayed maturation of auditory brainstem responses. Am J Clin Nutr 1998;68:683-690.

[39] Wachs TD, Pollitt E, Cueto S, Jacoby E, Creed-Kanashiro H: Relation of neonatal iron status to individual variability in neonatal temperament. Dev Psychobiol 2005;46:141-153.

[40] Burden MJ, Westerlund AJ, Armony-Sivan R, Nelson CA, Jacobson SW, Lozoff B, et al.: An event-related potential study of attention and recognition memory in infants with iron-deficiency anemia. Pediatrics 2007;120:e336-e345.

[41] Geng F, Mai X, Zhan J, Xu L, Zhao Z, Georgieff M, et al. Impact of fetal-neonatal iron deficiency on recognition memory at 2 months of age. J Pediatr 2015;167:1226-1232.

[42] Jáuregui-Lobera I. Iron deficiency and cognitive functions. Neuropsychiatr Dis Treat 2014;10:2087-2095.

[43] Cusick SE, Georgieff MK. The role of nutrition in brain development: the golden opportunity of the "first 1000 days." J Pediatr 2016;175:16-21.

[44] Algarin C, Karunakaran KD, Reyes S, Morales C, Lozoff B, Peirano $P$ et al.: Differences on brain connectivity in adulthood are present in subjects with iron deficiency anemia in infancy. Front Aging Neurosci 2017:9:54-63.

[45] Pivina L, Semenova Y, Doşa MD, Dauletyarova M, Bjørklund G. Iron deficiency, cognitive functions, and neurobehavioral disorders in children. J Mol Neurosci 2019;68:1-10.

[46] Sundagumaran H, Seethapathy J. Auditory brainstem response in infants with iron deficiency anemia. Int J Pediatr Otorhinolaryngol 2019;117:78-81

[47] Chowdhury SD, Ghosh T. Serum iron deficiency was associated with lower cognitive development in the children of the Santal tribe of West Bengala. Acta Paediatr 2020 Feb 19. doi: 10.1111/apa.15239. [Epub ahead of print].

[48] Hershko C. Assessment of iron deficiency. Haematologica 2018;103:1939-1942

[49] Wood SK, Sperling R. Pediatric screening: development, anemia, and lead. Prim Care 2019;46:69-84

[50] Auerbach M, Adamson JW. How we diagnose and treat iron deficiency anemia. Am J Hematol 2016;1:31-38.

51] WHO (2016) Guideline: daily iron supplementation in infants and children. In: Committee GR (ed) World Health Organization (WHO). Switzerland, Geneva.

[52] Mattiello V, Sizonenko S, Baleydier F, Bernard F, Diezi M, Renella R. Iron deficiency with and without anemia in children: a brief update for caregivers. Rev Med Suisse 2019;15:376-381.
[53] Haldeman MS, Nolan MS, Ng'habi KRN. Human hookworm infection: Is effective control possible? A review of hookworm control efforts and future directions. Acta Trop 2020;201:1-7.

[54] Özdemir N. Iron deficiency anemia from diagnosis to treatment in children. Türk Ped Arş 2015;50:11-19.

[55] Mattiello V, Schmugge M, Hengartner H, von der Weid N, Renella R. Diagnosis and management of iron deficiency in children with or without anemia: consensus recommendations of the SPOG Pediatric Hematology Working Group. Eur J Ped 2020;179:527-545.

[56] Węgier LP, Kubiak M, Liebert A, Clavel T, Montagne A, Stennevin A et al. Ferrous sulfate oral solution in young children with iron deficiency anemia. Pediatr Int 2020 Mar 19. doi: 10.1111/ped.14237. [Epub ahead of print].

[57] Christian P, Murray-Kob LE, Khatry SK, Katz J, Schaefer BA. Prenatal micronutrient supplementation and intellectual and motor function in early school-aged children in Nepal. JAMA 2010;304:2716-2723.

[58] Moya-Alvarez V, Bodeau-Livinec F, Cot M. Iron and malaria: a dangerous liaison? Nutr Rev 2016;74:612-623.

[59] Ghanchi A, James PT, Cerami C. Guts, germs, and iron: a systematic review on iron supplementation, iron fortification, and diarrhea in children aged 4-59 months. Curr Dev Nutr 2019;3:1-13.

[60] Neuberger A, Okebe J, Yahav D, Paul M. Oral iron supplements for children in malaria-endemic areas. Cochrane Database Syst Rev 2016; 2: CD006589.

[61] Grenov B, Larnkjær A, Mølgaard C, Michaelsen KF. Role of milk and dairy products in growth of the child. Nestle Nutr Inst Workshop Ser 2020;93:77-90.

[62] Peña-Rosas JP, Mithra P, Unnikrishnan B, Kumar N, De-Regil LM, Nair NS et al. Fortification of rice with vitamins and minerals for addressing micronutrient malnutrition. Cochrane Database Syst Rev 2019 Oct $25 ; 2019(10)$

[63] Garcia-Casal MN, Peña-Rosas JP, De-Regil LM, Gwirtz JA, Pasricha SR. Fortification of maize flour with iron for controlling anaemia and iron deficiency in populations. Cochrane Database Syst Rev. 2018 Dec 22;12:CD010187.

[64] Georgieff MK, Krebs, NF, Cusick SE. The benefits and risks of iron supplementation in pregnancy and childhood. Annu Rev Nutr 2019;39:121-146.

[65] Gupta S, Habeych E, Scheers N, Merinat S, Rey B, Galaffu N et al. The development of a novel ferric phytate compound for iron fortification of bouillons (part I). Sci Rep 2020;10:5340-5348.

[66] Dutra-de-Oliveira JE, Marchini JS, Lamounier JA, de Almeida CAN A new family home approach to controlling iron deficiency anemia in all ages in less-developed and developing countries using ironfortified water. Arch Latinoam Nutr 2016;66:159-164.

[67] Helman SL, Anderson GJ, Frazer DM. Dietary iron absorption during early postnatal life. Biometals 2019;32:385-393. 